Int. J. Electrochem. Sci., 14 (2019) $7026-7036$

\title{
Electrochemical Corrosion Performance of FSSP-Modified Copper Alloy Surface
}

\author{
Wei-wei Song ${ }^{1,2,3, *}$, Dun-wen Zuo ${ }^{2}$, Xiao-jing Xu ${ }^{3}$, Hong-feng Wang ${ }^{1}$, Sheng-rong Liu ${ }^{1}$ \\ ${ }^{1}$ College of Mechanical and Electrical Engineering, Huangshan University, Huangshan 245041, \\ P. R. China \\ ${ }^{2}$ College of Mechanical and Electrical Engineering, Nanjing University of Aeronautics and \\ Astronautics, Nanjing 210016, P. R. China \\ ${ }^{3}$ School of Mechanical Engineering, Jiangsu University, Zhenjiang 212013, P. R. China \\ *E-mail: sww_2011@163.com
}

doi: $10.20964 / 2019.08 .23$

Received: 4 April 2019 / Accepted: 4 June 2019 / Published: 30 June 2019

This study proposed a method using the friction stir surface processing (FSSP) technology to modify the surface layer of copper alloy and hence improve its corrosion resistance. H62 copper alloy was used for the purpose. The modification parameters in the FSSP were set as follows: rotation speed, $1200 \mathrm{rpm}$; traversing speed, $150 \mathrm{~mm} / \mathrm{min}$; and depth $0.15 \mathrm{~mm}$. The findings revealed that the surface of the modified sample with a depth of $0.15 \mathrm{~mm}$ had a higher degree of metallographic refinement and better hardness and corrosion resistance. The modified samples after one, two and three passes were compared. It was found that the metallographic structure of the two-pass modified samples was fine and uniform, and the hardness and corrosion resistance were the best, followed by the one-pass modification, with the three-pass modification being the worst.

Keywords: Electrochemical corrosion; friction stir surface processing; FSSP; H62 copper alloy; modified surface; weight loss

\section{$\underline{\text { FULL TEXT }}$}

(C) 2019 The Authors. Published by ESG (www.electrochemsci.org). This article is an open access article distributed under the terms and conditions of the Creative Commons Attribution license (http://creativecommons.org/licenses/by/4.0/). 